NASA

Technical Memorandum 83739

N $84-32: 57$ USAAVSCOM

Technical Report 83-C-16

\title{
Investigation of the Three-Dimensional \\ Flow Field Within a Transonic Fan Rotor: Experiment and Analysis
}

Michael J. Pierzga

Propulsion Laboratory

AVSCOM Research and Technology Laboratories

Lewis Research Center

Cleveland, Ohio

and

Jerry R. Wood

Lewis Research Center

Cleveland, Ohio

Prepared for the

Twenty-ninth Annual International Gas Turbine Conference sponsored by the American Society of Mechanical Engineers Amsterdam, The Netherlands, June 3-7, 1984 


\title{
INVESTIGATION OF THE THREE-DIMENSIONAL FLOW FIELD WITHIN A TRANSONIC
}

\section{FAN ROTOR: EXPERIMENT AND ANALYSIS}

\author{
Michael J. Plerzga \\ Propulsion Laboratory \\ U.S. Army. Research and Technology Laboratories (AVSCOM) \\ Cleveland, Ohio 44135 \\ and \\ Jerry R. Wood \\ National Aeronautics and Space Administration \\ Lewis Research Center \\ Cleveland, ohio 44135
}

\begin{abstract}
SUMMARY
An experimental investigation of the three-dimensional flow field through a low aspect ratio, transonic, axial-flow fan rotor has been conducted using an advanced laser anemometer (LA) system. Laser velocimeter measurements of the rotor flow field at the design operating speed and over a range of through-flow conditions are compared to analytical solutions. The numerical technique used herein yields the solution to the full, three-dimensional, unsteady Euler equations using an explicit time-marching, finite volume approach. The numerical analysis, when coupled with a simplified boundary layer calculation, generally yields good agreement with the experimental data. The test rotor has an aspect ratio of 1.56 , a design total pressure ratio of 1.629 and a tip relative Mach number of 1.38 . The high spatial resolution of the LA data matrix ( 9 radial by 30 axlal by 50 blade-to-blade) permits detalls of the transonic flow field such as shock location, turning distribution and blade loading levels to be investigated and compared to analytical results.
\end{abstract}

\section{INTROOUCTION}

Advancement in the aerodynamic design of gas turbine engine fans, compressors and turbines have historically resulted primarlly from an empirical approach. Although this approach has led to more efficient, lighter-weight engines, major new advancements in component performance will most likely not result from empiricism alone. A fundamental understanding of the complex flow phenomena which occur within advanced turbomachines is essential if significant advancements in performance are desired. As the cost of building and testing gas turbine engine components increases so does the need to reduce the number of redesigns necessary to achieve the desired performance. The need for redesigns is inherent in design systems which rely heavily on empirical correlations. There exists a need to develop design systems which rely less on empirical correlations and more on procedures which are capable of calculating those aspects of the internal flow field for which the correlations were developed. The development of these new design systems will require extensive ex-. perimental investigations of the intra-blade flow fleld to determine their validity. 
In addressing this need, the NASA Lewis Research Center, in cooperation with the Army Propulsion Laboratory, has undertaken a program designed to increase the basic understanding of the complex internal flows of gas turbine fans and compressors. The program relies primarliy on the use of nonintrusive optical techniques to evaluate the intra-blade flow fleld of transonic compressor blading. Concurrently, advanced computational techniques are being developed which incorporate the three-dimensional flow fleld effects of this class of turbomachine. A combination of experimental observation and computational experfence should lead to a better understanding of these complex flows and ultimately to major strides in gas turbine design technology.

Previous researchers have presented comparisons between three-dimensional flow calculations and internal flow fleld measurements (refs. 1 and 2). They have generally found that inviscid codes model the inlet to transonic rotors quite well but tend to over predict the deceleration through the rotor. This is usually attributed to lack of the streamline displacement effects due to boundary layer growth. Those who have added boundary layer calculations to three-dimensional analyses (refs. 3 and 4 ) have found that the flow field is substantially altered by addition of the displacement thickness to the solid surfaces. The technique used in reference 3 included simple models for shockboundary layer interaction, laminar-turbulent transition, and separation effects. The boundary layer calculations were performed only on the blade surfaces and yielded better agreement with experimental data than did the calculations without boundary layer effects. In reference 4 results were shown for the same rotor analyzed in reference 1 and demonstrated the extent to which inclusion of a simple boundary layer model on the blades and endwalls could alter the flow field in a transonic rotor.

The focus of the present work is the investigation of a detalled set of optical measurements of an advanced transonic, axial-flow compressor flow field obtained under the current NASA/Army research program. These data, coupled with the results of an inviscid, three-dimensional flow fleld calculation, provide the basis on which the internal flow features and trends are interpreted herein. Strazisar (ref. 5) provides a more fundamental overview of the rotor flow physics, including the three-dimensional nature of the shock fronts based on these same data.

\section{COMPRESSOR ROTOR}

The research vehicle used in the present work was the first-stage rotor of a NASA Lewis designed two-stage fan (ref. 6). The first-stage rotor was designed as a 22 blade, low aspect ratio (1.56), damperless replacement for the original 43 blade, high aspect ratio (2.94), dampered rotor (ref. 7 ). The new blading met or exceeded its design total pressure ratio and adiabatic efficlency goals of 1.629 and 0.896 , respectively, when tested in the two-stage configuration. The inlet relative Mach number at the rotor tip was 1.38 at the design tip speed of $428.9 \mathrm{~m} / \mathrm{s}$ and design mass flow rate of $33.25 \mathrm{~kg} / \mathrm{s}$.

The rotor was tested in the present work without inlet guide vanes or downstream stators so that blade row interactions would not be present. Figure 1 shows the measured rotor performance characteristic for a constant design speed condition. Also shown in the figure, for reference purposes, are data from the redesigned two-stage fan investigation (ref. 6). Herein, all 
future reference to rotor performance will deal solely with the isolated rotor data.

The entire experimental research program conducted with the isolated rotor configuration of this low aspect ratio fan covered a range of data points from max flow (MF) to near stall (NS); however, the most detailed information was obtained at the peak efficiency (PE) and near stall points. Most of the comparisons between experiment and computation will be restricted to these two flow points.

\section{INSTRUMENTATION}

A fringe laser anemometer system (LA) was the principal instrument used during the experimental evaluation program. This instrument is a singlechannel, dual beam system with an on-axis backscatter collection scheme and has been previously described in detail (refs. 8 and 9). Data aquisition and storage was accomplished via a dedicated minicomputer while post processing and graphical output was handled by a large central computer. Access to the compressor flow path was through a $3 \mathrm{~mm}$ thick glass window which extended far enough foreward and aft of the test rotor to enable free-stream and blade wake measurements. The window curvature closely conformed to the rotor outer flow path, thereby minimizing disturbances to the tip region flow. Fluorescent seed particles, whose nominal diameter was 1 to $1.4 \mu \mathrm{m}$, were spray atomized into the flow stream through a $6 \mathrm{~mm}$ diameter tube located over $60 \mathrm{~cm}$ upstream of the rotor leading edge. In addition to LA measurements, conventional instrumentation was used to record compressor overall pressure and temperature levels. This information was used to calculate the compressor overall performance characteristic as well as to control the on-line operating condition set point.

\section{DATA COLLECTION}

The precise rotor-relative location of each LA velocity measurement was determined using a pulse from a variable frequency oscillator which was phaselocked to the rotor rotational speed. All of the data presented herein were collected with the oscillator set at 50 pulses per blade passage and a maximum blade survey range of 17 passages. The blade geometry was used to set the first measurement position (shaft position) to coincide with the suction surface of a known blade. Since the data collection windows were equally spaced with no circumferential gaps, some data were acquired at shaft positions which were physically within the rotor blade. Data collected in these areas were handled in the off-line reduction of the data, to be discussed later. This method of surveying across a number of blade passages allowed for a larger overall data collection window as well as provided the ability to investigate passage to passage flow varlations. It is not within the scope of the present work to look at such.passage dependency among the data, and thus all of the blade passages were ensemble averaged to yield an "average" blade passage data set. A typical data run consisted of collecting 60000 velocity measurements within the entire data collection window at each axial survey location. This ylelded approximately. 70 measurements at each of the 850 shaft positions or 1200 averages for the 50 "average" shaft positions. Time to collect the 60000 measurements was approximately $60 \mathrm{sec}$ for each of the two velocity components measured at each shaft position. The two angular orientations of the 
LA probe volume used to obtain the velocity components was predetermined from an initial screening run at each LA survey span location and flow rate. The pitchwise-averaged, flow angle at several axial stations along the survey streamsurface was obtained from this screening run. The two LA fringe orientations used in the data runs were derived by bracketing this mean flow angle by twenty degrees.

The laser anemometer survey locations along with the meridional view of the computational grid used by the three-dimensional analysis code are shown in figure 2(a). The LA blade-to-blade matrix is shown in figure 2(b). LA survey locations, denoted by solid circles in figure 2(a), were axially distributed at specific locations based on the axial projection of the local chord length along design streamlines to provide data coverage at 20 percent intervals upstream, 2.5 percent intervals around the leading edge, 10 percent intervals within the blade and five eveniy spaced locations between the rotor trailing edge and the position of the stage configuration stator leading edge. Survey points were also included at the conventional instrumentation survey planes (stations. 1 and 2), as shown in the figure. The radial distribution. of survey points was along design streamlines which pass geometrically through desired percent span positions at the rotor trailing edge plane. This radial position designates the particular LA survey streamiline such as $10,20,30$ percent and so on. The nine radial immersions used in the experimental investigation were spaced at 10 percent span intervals, beginning at 10 percent from the rotor tip and coincided with nine of the three-dimensional computational planes.

\section{NUMERICAL ANALYSIS}

The numerical analysis of the rotor was conducted using a threedimensional computational procedure developed by Denton (ref. 10). This procedure was based upon a finite volume technique. The code was modified (ref. 4) to include the effects of boundary layer displacement using an injected mass technique, which allowed flow to pass through the walls in proportion to the rate of growth of the boundary layer displacement thickness. The boundary layers were calculated as if the grid lines in the streamwise direction were actual flow field streamlines. Boundary layers were calculated on both the blade surfaces and on the endwalls which were assumed to rotate with the blading. The displacement thickness was computed from the von Karman integral boundary layer equation using a constant shape factor (1.5) and constant skin friction coefficient $(0.005)$. Setting the shape factor to a constant value limits the growth of the displacement thickness in regions of sharp adverse pressure gradients and could significantly effect the results. However, increasing the complexity of the computational procedure could lead to significant increases in computer time. Thus, the decision was made to evaluate the present rotor using the simplified procedure in order to assess its effect on the flow field solution.

The upstream boundary was located 1.5 times the tip axial chord upstream for the tip and 0.7 times the hub axial chord upstream for the hub. At the upstream boundary the total pressure, total temperature, absolute tangential velocity, and meridional flow angle were held constant at each spanwise grid line and assumed to be uniform in the tangential direction. The only downstream condition specified was the static pressure at the hub, and it was 
assumed to be constant in the tangential direction. The static pressure gradlent from hub to tip at the downstream boundary was calculated assuming no curvature of the streamlines in the hub-to-shroud plane which was appropriate for this case based upon the flow path geometry. The downstream boundary was located twice the tip axial chord downstream at the tip and one hub axtal chord downstream at the hub.

All of the solutions presented were obtained with a computational grid of 21 points blade-to-blade, 95 points in the streamwise direction with 50 points from blade leading to tralling edge (fig. 3) and 11 points from hub-to-shroud. A large number of computational points was used in the present work so that any discrepancies between analysis and data could not be attributed to use of a coarse grid. The peak efficlency point was repeated with the number of bladeto-blade points reduced from 21 to 11 . The solution showed that the major difference between the coarse grid solution and the fine grid solution was a small change in location of the shock and in the relative Mach number ahead of the shock at the transonic sections. The shock also tended to be smeared slightly more with the coarse grid than with the fine grid. Evaluation of the computational method in terms of sensitivity of the code to grid size is not within the scope of the present work and is mentioned only to provide the reader with an indication of its importance for this rotor at this one flow point. The sensitivity of the solution to blade-to-blade grid spacing was not checked for the other flow conditions analyzed. Streamwise grid spacing was constant on the blading but was expanded upstream and downstream in order to isolate the boundaries from the leading and trailing edges with as few points as necessary in an attempt to capture the correct upstream wave strength and to limit the effect of a uniform circumferential pressure at the downstream boundary. In all cases multigrid ( 7 by 12 by 3 ) with a nonuniform timestep was used.

The boundary layer displacement thickness was updated every 50 timesteps with 50 percent of the new displacement thickness added to 50 percent of the previous value. Fractional updating of the boundary layer was necessary since full correction tended to produce instability. met:

Convergence was assumed to occur when all the following conditions were

(1) The maximum change in axial velocity anywhere in the flow field divided by the root-mean-square of all the absolute velocities in the flow field did not exceed 0.01 percent.

(2) Mass flow at each streamwise grid line agreed with the inlet mass flow to within 0.3 percent.

(3) Inlet mass flow did not change by more than 0.3 percent over several hundred timesteps.

(4) Mach numbers at four selected positions on the rotor suction surface did not change by more than 0.02 over several hundred timesteps:

The foregoing conditions. listed above are rather stringent for this case and may not be required for other blade rows. The 0.01 percent restriction on axial velocity change could be relaxed to 0.02 in this case with little change 
in the solutions. The criterion for change in inlet mass flow rate was necessary for this blade row operating at near its peak efficiency point. For operation at lower than peak efficiency flow, small changes in mass flow rate are not as important and that condition could have been relaxed. During initial runs to establish the proper pressure ratio in order to set the peak efficiency flow, several solutions were obtained at flows very near that for peak efficiency (mass flow ratios of 0.984 and 0.998 versus the peak efficiency value of 0.992$)$. At 10 percent span from the tip for both flows the shock on the suction surface moved approximately 15 percent of axial chord from the position obtained at peak efficiency. For the higher flow, the shock on the pressure surface moved rearward by about 20 percent of axial chord and increased in face Mach number from about 1.23 to 1.36 .

The code as described in reference 4 did not satisfy the boundary condition at a solid surface requiring the velocity normal to the surface to be zero. Because of this, there are areas in the flow where the velocity does not have a zero normal component to a solid surface. This is particularly true around the leading edge of a blade and at points where a strong shock hits the solid surface. All solutions presented herein were produced with this condition at the solid surfaces. In order to check the effects on the solutions presented, the normal velocities were set at zero (ref. 11 ) at the solid surfaces and the flow point at peak efficiency repeated. Very little difference was found in the final solutions when judged in terms of line plots of near-blade relative Mach number and flow angles. The flow angle did conform to the blade angle at the surface but at one grid point off the blade the flow angles for the two cases with and without the zero normal velocity condition imposed were very similar. The major differences occurred at the percent span locations near the hub, where the leading edge is thick. Mach numbers on the suction surface were silghtly higher than those obtained without the normal velocity set to zero. The shock location at all spanwise stations on the suction surface was the same for both cases. The numerical error in total pressure increased near the hub sections when the zero normal velocity condition was imposed.

For the computations with the boundary layers included, timesteps to convergence ranged from 2486 for the peak efficiency case (where the location of the shock is very sensitive to even small mass flow changes) to 1300 at the maximum flow condition. Computation times on a Cray- 1 computer were 17 and $9 \mathrm{~min}$, respectively. Computation time on an IBM 370-3033 would be approximately 10 times as long. No appreciable increase in time resulted from use of the boundary layer calculations. The solution actually converged somewhat better with the boundary layer calculations than without.

\section{DATA PRESENTATION}

Due to the large quantity of experimental data collected, over 32.5 million velocity measurements per operating point, data presentation represents a major effort and concern. To compare the overall flow features observed in the experimental and analytical data, contour maps of relative Mach number are most useful. Experimental data, however, do not usually produce good quality. contour maps. The background noise, nonuniform survey location spacing, problems associated with LA blade flash and data drop-out all contribute to poor quality plots. Analytical data, on the other hand, has very few of these problems as evidenced by the quality of such contour maps. 
To avoid constructing contours of experimental data by hand for each flow condition surveyed, a method has been developed to "enhance" the LA data, without altering its informational content, such that it becomes suitable for computer generated contour plots. The following procedure was used to enhance the data before presentation:

(1) Each blade-to-blade data window was first screened to confirm that there were at least one hundred LA measurements obtained and that the window circumferential extent did not overlap the pressure surface of a blade. If efther condition was not satisfied the recorded velocity value was set equal to zero.

(2) An interpolation procedure was then used to establish values to fill the zero velocity data windows using information from adjacent survey points in both the streamise and pitchwise directions. This method allowed information from both directions to influence the final interpolated value. Once the areas of zero velocity had been interpolated, the pitchwise data was smoothed such that a maximum change due to the smoothing was 1 imited to 0.5 percent of the original value. This amount of smoothing removed the high frequency noise in the data without distorting the highly desirable velocity gradient regions of the flow field.

(3) These nonzero velocity data were then used to increase the streamwise data density by interpolating along preferred directions. Streamwise data density of 2.5 percent of axtal chord was necessary to achieve the desired contour map quality.

(4) Finally, these data were smoothed in the chordwise direction to eliminate small oscillations due to acquisition noise in the original data as well as possible peaks due to the interpolation procedure. The smoothing procedure permits a maximum change at any point of 0.5 percent of the unsmoothed value.

Figure 4 shows contours of relative Mach number for the 30 percent span immersion survey location at peak efficiency operation. Figure $4(a)$ represents a relative Mach number contour map using only the raw LA data including zero velocity values and blade interlor values. Figure $4(b)$ shows the improvement that can be achleved with simple removal and replacement of "bad" data and a small amount of smoothing. Figure $4(c)$ shows the effect of increasing chordwise data density where data has been interpolated to every 2.5 percent axial chord. Finally, figure $4(d)$ shows the contour map which results from the screened, chordwise interpolated, smoothed data. As shown, the enhancement procedure enables reasonable contour maps to be constructed without changing the basic information found in the data that was not enhanced. This enhancement procedure along with a four-step check simtlar to that shown in figure 4 was used to generate all of the remaining contour maps presented and to make certain that the enhancement process only clarified the contour plots and did not produce new features in the flow fleld.

\section{RESULTS AND DISCUSSIONS}

Introduction. - The data presentation initially focuses on the use of contour maps of relative Mach number to show changes in flow conditions as the 
rotor exit pressure was changed. Comparisons are made between the analysis code and the results obtained with the laser anemometer. Results are also presented in terms of overall pressure rise and turning as measured and predicted. Plots of relative Mach number at various flow rates and percent spans are shown to give a more detalled picture of the flow in a quantitative sense. In each line plot the analysis is compared to the LA data at comparable percent gap locations. Finally, some applications of the results which might have significance in the design of future compressor blading is addressed.

Mass flow rates measured in experimental facilities and calculated numerically have a degree of uncertainty associated with them such that comparison of absolute magnitudes may not match well. To compensate for this fact, all of the comparisons are made at mass flow rates that have been nondimensionalized with the maximum flow rate measured from the experiment or calculated by the analysis code as approprlate. Although this approach was taken, the agreement between the predicted maximum flow and the experimental measurement was excellent for both the runs without and with boundary layer calculations. The maximum flow predicted without boundary layers was 1.2 percent higher than the measured flow and that predicted with boundary layers was only 0.06 percent higher.

\section{Relative Mach Number Contours}

Thirty percent span. - Figure 5 is a composite showing the results obtained with the laser anemometer and analysis code at 30 percent span for the three flow conditions; max flow, peak efficiency, and the near-stall point. The shock locations are shown for each flow rate in order to provide a clearer picture of the flow in the passage. Locations of the wave systems and shocks were determined by inspection of relative Mach number and relative flow angle data with respect to the streamwise direction and designating the starting point of the flow deceleration as the shock front. This was done at as many pitchwise locations as needed for the desired resolution. Experimental LA data must be interpreted in this manner due to possible seed particle lag once a high velocity gradient region is encountered. The numerical calculation actually produced shocks that were smeared over several grid points and thus the actual location of the shock is between the beginning and ending of the deceleration. The grid spacing used herein was small, and the shocks were assumed to be located at the beginning of the deceleration.

The LA data in figure 5 shows the progression from an oblique shock at max flow with supersonic flow in the aft portion of the blading, to a near normal shock followed by a second shock at peak efficiency, and finally, a single normal shock ahead of the blade leading edge at the near stall point. The peak Mach number varies from 1.4 ahead of the shock at max flow and peak efficiency to 1.35 ahead of the shock at near stall. Also shown in the figure are the results obtained with the three-dimensional analysis code. The major difference between the experiment and analysis at max flow is the location of the second shock at the exit of the passage. The peak Mach numbers upstream of the first shock are approximately equal. Although, the location of the second shock is sensitive to backpressure at the max flow condition, a 7 percent increase in backpressure was required in order to move the computed shock to the approximate position of the measured second shock. This is a large change in pressure, and it is more probable that the difference in location is a result 
of the constant shape factor used in the boundary layer calculations. Also, LA data in the aft portion of the rotor for the max flow condition was only taken at the 40,60,90 and 100 percent chord locations so that good shock definition in this region was very difficult. The Mach number at the rotor exit is less for the numerical results at this flow point than the measurements indicate (an exit Mach number of about 0.95 for the data and 0.9 for the analysis).

The agreement at the peak efficiency point between the data is much better than for the max flow case. The front shock is accurately located by the code and there is a rear shock located in approximately the same position as the measured rear shock. The second shock is shown extending from the pressure surface to about midpitch. At points closer to the suction surface, interpreting the location of the shock was more difficult since an acceleration of the flow or a constant Mach number region was not found in the streamwise plots. However, indications of a second shock were found near the suction surface by noting changes in the Mach number gradient in the streamwise direction. This was true for both the analysis and the LA data. The computed Mach number in the exit region of the blade is lower than the measured Mach number 10.8 compared to 0.9). Peak Mach number upstream of the shock is 1.4 for both the data and the analysis. The agreement between analysis and data at the near stall point is good in terms of shock location and peak Mach number. The computed Mach number at blade exit is underpredicted $(0.7$ versus 0.8$)$, as it was with the previous cases.

Near tip and near hub sections. - Figure 6 shows the peak efficiency and near stall flow points at the 10 percent span location (fig. 6(a)) where the inlet relative Mach number is supersonic and at the 70 percent span location (fig. 6(b)) where the inlet relative Mach number is subsonic. Results are shown for both the experiment and the analysis. The peak efficiency LA data at 10 percent span in figure. 6(a) shows a front shock that is nearly normal around the leading edge but is oblique over most of the passage gap. Inspection of the streamwise and pitchwise LA data indicated that a second shock might exist. However, the data was not conclusive and thus a second shock is not indicated in the figure. A second shock was predicted by the three-dimensional analysis code at the approximate location suggested by the LA data. The high values of relative Mach number after the normal portion of the shock have been investigated by Strazisar (ref. 5) and appear to be due to the three-dimensional shock inclination in the hub-to-shroud plane.

At the near stall point the second shock has disappeared from the analysis and only a normal shock standing in front of the blade remains. A second shock system on the pressure surface around the leading edge is indicated by the LA data. This feature appears to be necessary to guide the high incidence angle flow around the leading edge so that it can adjust to the blade surface angles. This assumption was supported by computing particle trajectories through this proposed system based on the wave angles and the measured in let Mach number. Final pressure surface flow angles after passing through the second shock system were within a few degrees of the surface values. This phenomenon is not predicted by the analysis and may be due, at least in part, to tip region flow effects. More extensive analyses at other operating conditions and percent span locations with high incidence angles is required before a full explanation can be presented. Peak Mach numbers before the shock are, in both cases, approximately 0.1. higher for the analysis than for the data. Suction surface 
Mach numbers are generally higher $(0.1$ to 0.2$)$ in the analysis since the viscous effects are incorporated only as a mass addition and not a momentum deficit.

Figure $6(b)$ shows maps of constant relative Mach number for peak efficiency and near stall at the 70 percent span location for both the LA data and the three-dimensional analysis results. Flow field features between the two operating conditions are very similar and agreement between the LA data and the numerical results is quite good although the analysis yields a slightly lower exit Mach number than experimentally verified.

\section{Overall Performance}

In figure 7 an attempt has been made to provide a clear picture of how the three-dimensional analysis code compares to the experimental data on a global basis that could be useful in the design phase of a new blade row. Figure 7 (a) shows the static pressure rise across the rotor at the hub and tip as a function of nondimensional mass flow rate. As expected, the analysis without boundary layers predicted a much higher pressure rise at both hub and tip than was measured with conventional pressure instrumentation. Excellent agreement between the measurements and the analys is with boundary layer effects is experienced over the entire speed line from max flow to near stall. Unstable operation of the rotor was experimentally observed at a mass flow ratio of about 0.89 , whlle at a mass flow ratio of 0.906 the analysis was stable. The near-stall numerical solution was certainly aided by the restriction of a constant shape factor for the boundary layer calculations. Overall turning of the flow across the blade row at midpitch, given by rotor exit absolute tangential velocity divided by wheel speed is shown versus percent span for the peak efficiency and the near stall point in figure $7(b)$. Agreement between LA data and analytical results is within 30 percent at peak efficiency and less than 16 percent near-stall over the entire blade span. The pitchwise averages of the flow turning (not shown) agree within 21 percent at peak efficiency and within 15 percent for near stall. The temperature ratios across the rotor predicted by the analysis and preliminary data from standard aerodynamic survey probes (not shown) was compared at peak efficiency and found to agree within 2 percent over the entire span. This discrepancy between the LA results, analys is results, and standard.aerodynamic measurements is expected to be resolved by application of high frequency response pressure probes behind the rotor in future experiments.

\section{Relative Mach Number at MidPitch}

A more quantitative approach to comparison of the LA data and the analysis results is to look at data along the rotor midpitch line. It is precisely this type of plot which has been used to determine the shock front locations for all of the relative Mach number contour maps presented thus far. The relative Mach number along a midpitch line versus percent chord at 30 percent span for all three operating points is shown in figure 8 . The expansion of the flow after the first shock at max flow as predicted by the analys is code leads to a strong passage shock at approximately 70 percent chord. Some indication of a second shock in the max flow LA data is evident from the peak in Mach number at 10 percent chord, plateau from 30 to 40 percent chord and subsequent deceleration from 40 to 60 percent chord. Agreement in the front shock location 
between the analysis and experiment is good but, as before, a low exit Mach number is predicted by the analysis. The differences in the second shock location may be due in part to insufficient LA survey locations in this region. Only one LA data point exists between the start of the computed reexpansion and the rotor exit. At peak efficiency the two-shock system that was observed in earlier contour maps is again evident in the experimental data (shown by a plateau of Mach number from 20 to 30 percent chord) but not as evident in the analysis results. There is however, a change in the gradient of computed Mach number at 40 percent chord indicating the existence of the second shock. At percent gap. locations closer to the pressure surface, the gradient change becomes more pronounced until the existence of the second shock becomes evident. Shock location and peak Mach number before the shock agree well for both peak efficiency and near stall.

\section{Near-Blade Surface Comparisons}

Generally, an important task for the blade row designer is to tailor the blade shapes so that adverse gradients that produce large growths in the boundary layer are either reduced or controlled. It is of great concern to determine how well a particular analysis code predicts the surface velocities in order to determine how much faith the designer should place in the ability to tallor the blading for low losses. Blade loading in terms of differences in relative Mach numbers across the channel in the pitchwise direction versus percent chord are shown in figure 9 for 10,30 and 70 percent spans for both peak efficiency and near stall. The LA data is taken at the first point off the blade surface where a sufficlent number of measurements were avallable. This was generally close to 5 and 95 percent pitch and, therefore, the analysis results were selected at these same locations. For all three spanwise locations the agreement on loading levels is reasonably good at peak efficiency. At near stall, however, the analys is yields much higher loadings at 10 and 30 percent span but is reasonable at 70 percent. The major difference in the loading level results from lower computed Mach numbers on the pressure surface than measured. Suction surface agreement is generally good for both flow rates. For all percent span locations and flow points, the shock location on the suction surface is well-predicted by the analysis.

Another area which is of some interest to the turbomachinery designer is the manner in which the flow is turned through the blade row. Figure 10 shows the measured relative flow angle as a function of percent chord for both the suction and pressure surfaces. The results are shown for the 30 percent span immersion location and for all three operating conditions. Also shown in the figure are the blade surface metal angles. The measured suction surface flow angles show that generally the flow follows the suction surface throughout the entire operating range. The analysis results of suction surface flow angle follow many of the same trends observed in the LA data. Flow deviations from the suction surface metal angle in the aft portions of the blade are observed both experimentally as well as analytically with the amount of deviation increasing from peak efficiency to near stall operation. The axial location at which the flow deviates from the blade changes from about 90 percent chiord at peak efficiency to about 80 percent chord near-stall. The data at max flow is too sparse to determine where the flow deviates from the blading.

The pressure surface flow angle data in figure 10 appears not to be as well behaved as the suction surface data. Both analytical and experimental 
data follow the blade surface over most of the chord, except in the leading edge region. Figure $10(\mathrm{c})$ indicates that the pressure surface flow angle does not adjust and start to follow the pressure surface at near stall as quickly as it did at the other conditions. It is not unt 11 about 30 percent chord that the relative flow angle matches the blade angle. The analysis also indicated that the flow does not adjust to the blading immediately at near-stall, however it adjusted more rapidly than the LA data indicates.

\section{Analysis Results in the Meridional Plane}

Figure 11 shows the nature of the shock system and how the numerical result changes from peak efficiency to near stall. In this suction surface hubto-shroud view the shock inclination angle changes dramatically at radial positions between the t1p and 30 percent span while below 30 percent span, the inclination remains constant. The shock location changes from the aft portion of the blading near the tip to the front part of the blading near the hub. Overall, the Mach numbers in front of the shock increase as the operating point changes from peak efficiency to near stall. Since it is difficult to predict the point where stall will occur in the analysis, due to the use of a constant shape factor, one approach is to consider where the shock structure is strong enough to separate the boundary layer. The static pressure rise across a normal shock at a Mach number of 1.3 is generally considered sufficient to produce boundary layer separation. At the near stall flow, the Mach number contour at 1.3 penetrates to about 90 percent span from the tip and the inclination of the shock in the meridional plane decreases from that at peak efficiency. The shock is almost normal to the flow at near stall, and thus, the pressure rise across it is approaching that of a normal shock. The shock location has moved forward and occurs in front of the rotor throat. This combination could produce global separation on the blade and subsequent stall of the rotor. Information of this kind could be used for a new design to warn the designer of a potential stall condition.

\section{CONCLUDING REMARKS}

The comparisons between analytical and experimental data for a transonic, low-aspect ratio, axial-flow fan rotor have, in general, shown good agreement for all of the operating conditions presented. The overall trends in the relative Mach number contour maps indicate the very good shock capturing ability of the analysis code at all rotor span locations. The results presented have demonstrated the extent to which an inviscid Euler solver with a very simple boundary layer correction scheme was able to predict the complex threedimensional flow field of this transonic rotor flow field. The code predicted the maximum flow for the rotor extremely well. Results were also shown that indicate that the code may be useful in analysis of a new blade row design to insure that desired stall margin is attained. The chordwise plots of relative Mach number and relative flow angle reveal some areas in which analysis and LA data deviate. Some of these conditions may be traced to the boundary layer model used.

A three-dimensional analysis technique, such as the one used herein, would probably not be used in the preliminary design of turbomachinery blading, however it may well be used to check a final configuration for design and off- 
design operation. This capability to compute the off-design flow field is extremely important and has shown to yield reasonably good quantitative results for the present rotor configuration. The analysis code did not predict the multiple shock system on the pressure surface required to turn the flow paralle1 to the blade. This may have, been due to the numerical smoothing used in the code and should be investigated further. Results concerning the intrablade flow turning and work distribution should be useful information for compressor design systems.

As mentioned, the goal of the current NASA/ARMY research program is centered around increasing the fundamental understanding of the three-dimensional flow field of compressor blading. The material presented has been one such attempt to investigate the flow field of a particular transonic fan rotor, and as such, the results shown apply only for this case. Further work dealing with different types of blading is needed to determine how much of what was observed experimentally and computed numerically for this isolated rotor, is generic to this class of turbomachine and how much was rotor specific. As more machines are investigated, questions such as blade row interactions and multistage matching should also be addressed.

\section{REFERENCES}

1. Chima, R. V. and Strazisar, A. J., "Comparison of Two- and ThreeDimensional Flow Computations with Laser Anemometer Measurements in a Transonic Compressor Rotor," ASME Journal of Engineering for Power, vol. 105, no. 3, July 1983, pp. 596-605.

2. Sarathy, K. P.. "Computation of Three-Dimensional Flow Fields Through Rotating Blade Rows and Comparison with Experiment," ASME Journal of Englneering for Power, vol. 104, no. 2, Apr 11 1982, pp. 394-402.

3. Singh, U. K., "A Computation and Comparison with Measurements of Transonic Flow in an Axial Compressor Stage with Shock and Boundary Layer Interaction," ASME Journal of Englneering for Power, vol. 104, no. 2, Apri1 1982, pp. 510-515.

4. Denton, J. D., Lecture Notes, ASME Turbomachinery Institute Course on Fluid Dynamics of Turbomachinery, July 18-27, 1983.

5. Strazisar, A. J., "Investigation of Flow Phenomena in a Transonic Fan Rotor Using Laser Anemometry," NASA TM-83555, 1984.

6. Urasek, D. C., Gorre 11, W. T., and Cunnan, W. S., "Performance of TwoStage Fan Having Low Aspect Ratio First-Stage Rotor Blading," NASA TP-1493 and AVRADCOM TR 78-49, August 1979.

7. Cunnan, W. S., Stevans, W., and Urasek, D. C., "Design and Performance of a 427-Meter-Per-Second-Tip-Speed Two-Stage Fan Having a 2.40 Pressure Rat10," NASA TP-1314, October 1978.

8. Powell, A. J., Strazisar, A. J., and Seasholtz, R. G., "Efficient Laser Anemometer For Intra-Rotor Flow Mapping in Turbomachinery," ASME Journal of Engineering for Power, Vol. 103, No. 2, Apri1 1981, pp. 424-429. 
9. Strazisar, A. J., and Powe 11, J. A., "Laser Anemometer Measurements in a Transonic Axial Flow Compressor Rotor," ASME Journal of Engineering for Power, vol. 103, No. 2, Apr 11 1981, pp. 430-437.

10. Denton, J. D., "An Improved Time Marching Method for Turbomachinery Calculation," ASME Paper 82-GT-239, 1982.

11. Glassman, A. J., private communications, Lewis Research Center, November, 1983. 

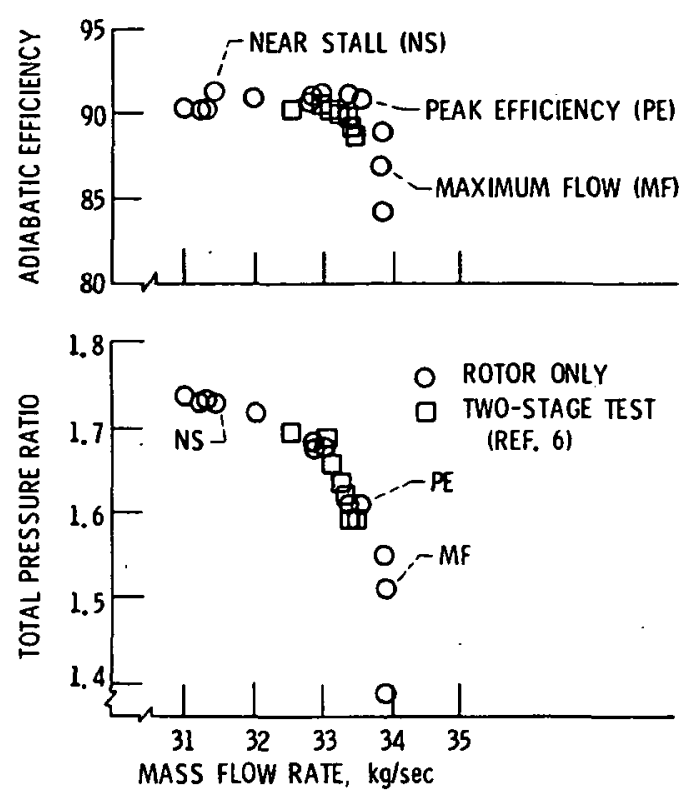

Figure 1. - Rotor performance at design speed.

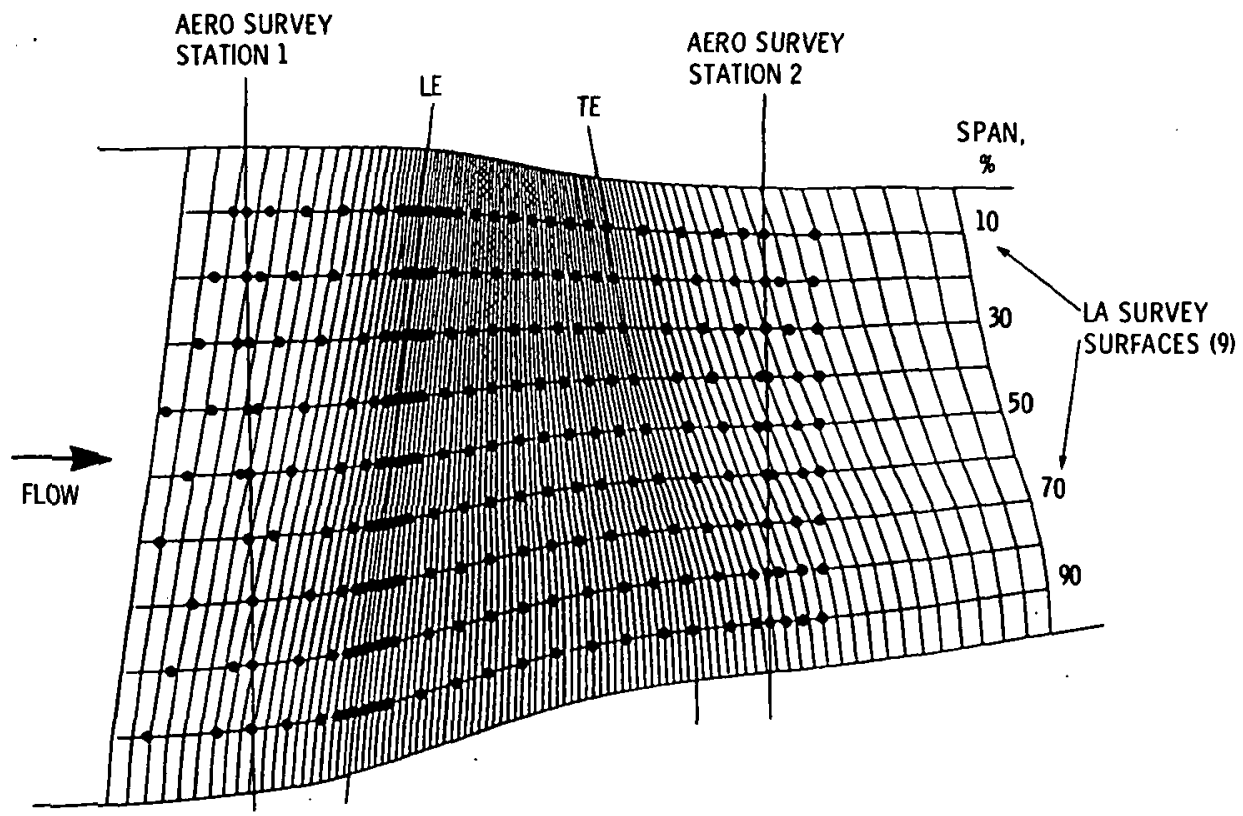

(a) Computational grid in the meridional plane with LA survey locations and standard aerodynamic survey planes. figure 2. - LA survey locations and their typical pitchwise distribution. 

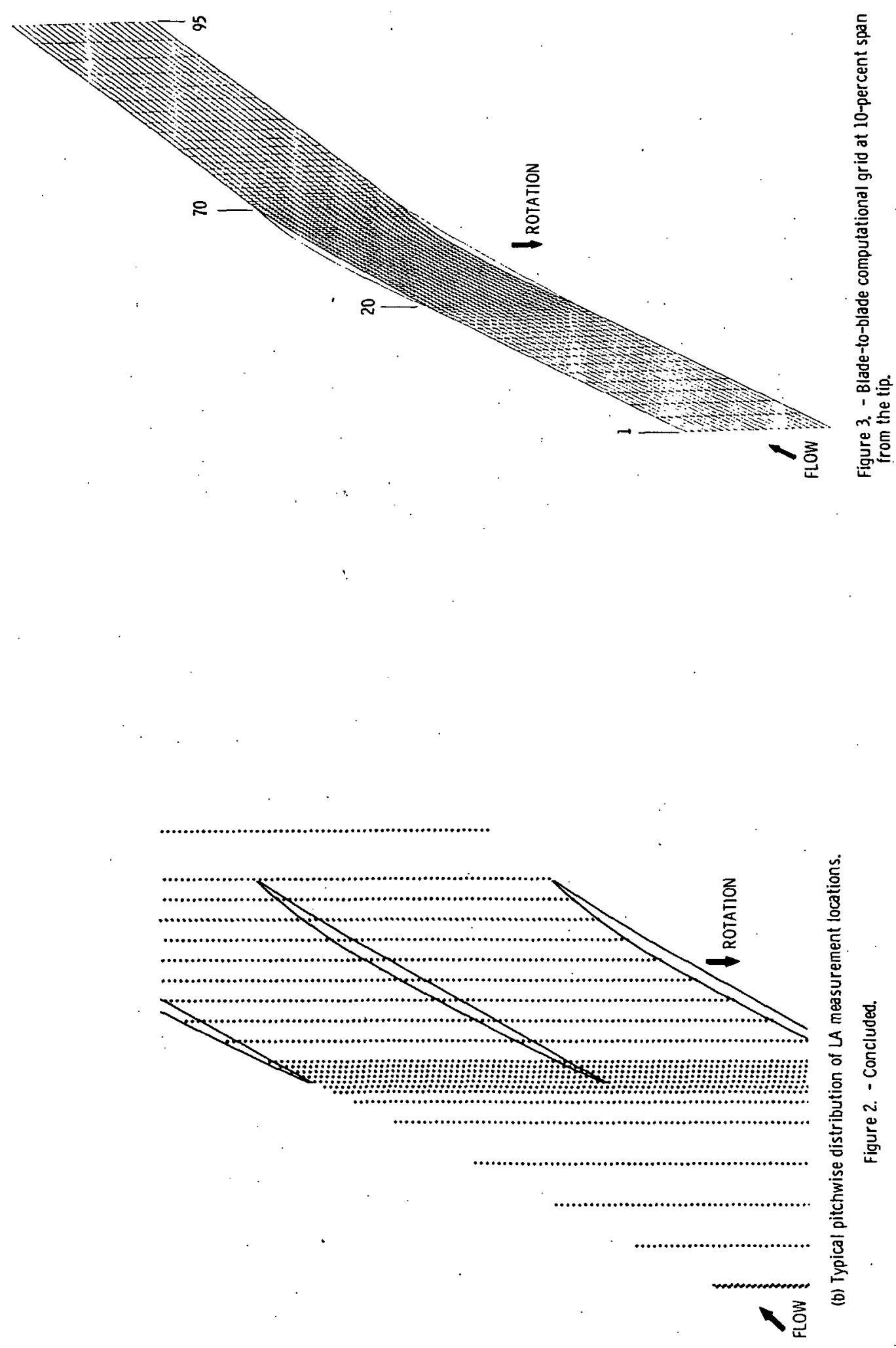


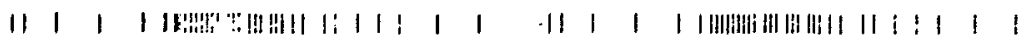
ACTUAL CHORDWISE LOCATIONS FOR LA DATA JEACTUAL CHORDWISE LOCATIONS FOR LA DATA

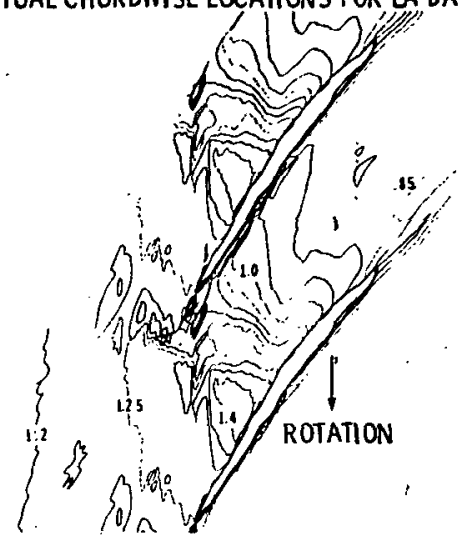

(a) Contour plot using "raw" data.

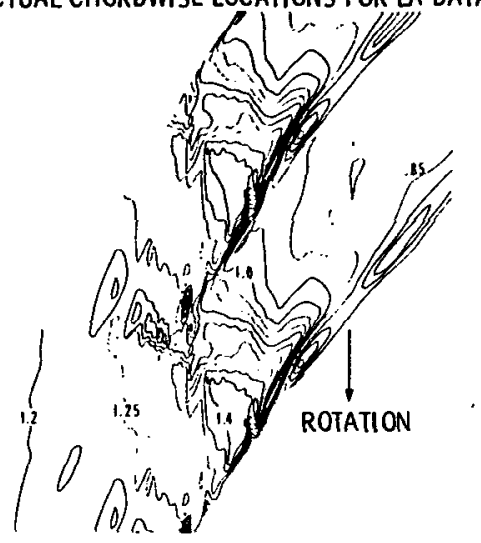

(b) Conour plot with all "zero" data removed.

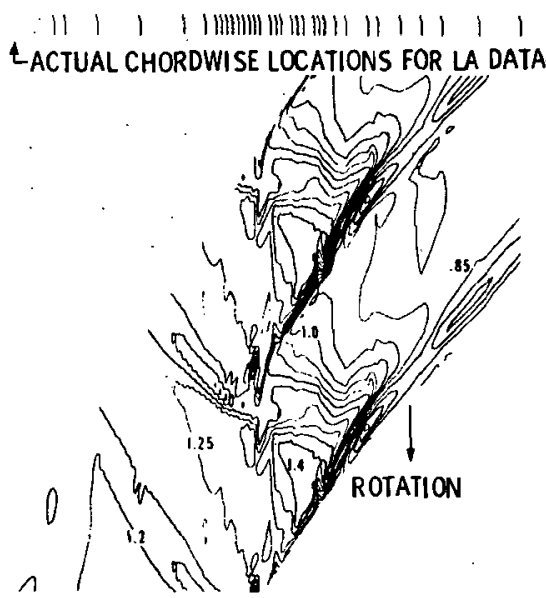

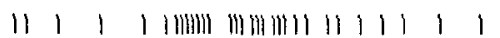
EACTUAL CHORDWISE LOCATIONS FOR LA DATA

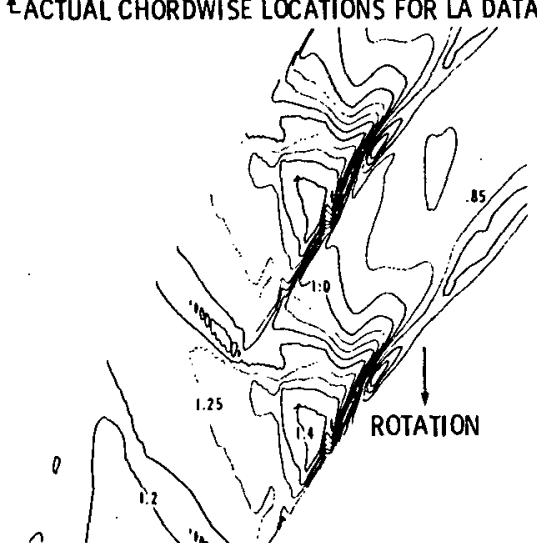

(c) Contour plot with data interpolated to increase

(d) Contour plot with final level of smoothing. the number of axial locations.

Figure 4. - Contour plots of relative Mach number at $30 \%$ span from the tip at the peak efficiency flow rate showing the effect of the enhancement process on the LA survey data. INote: blades not shown.) 

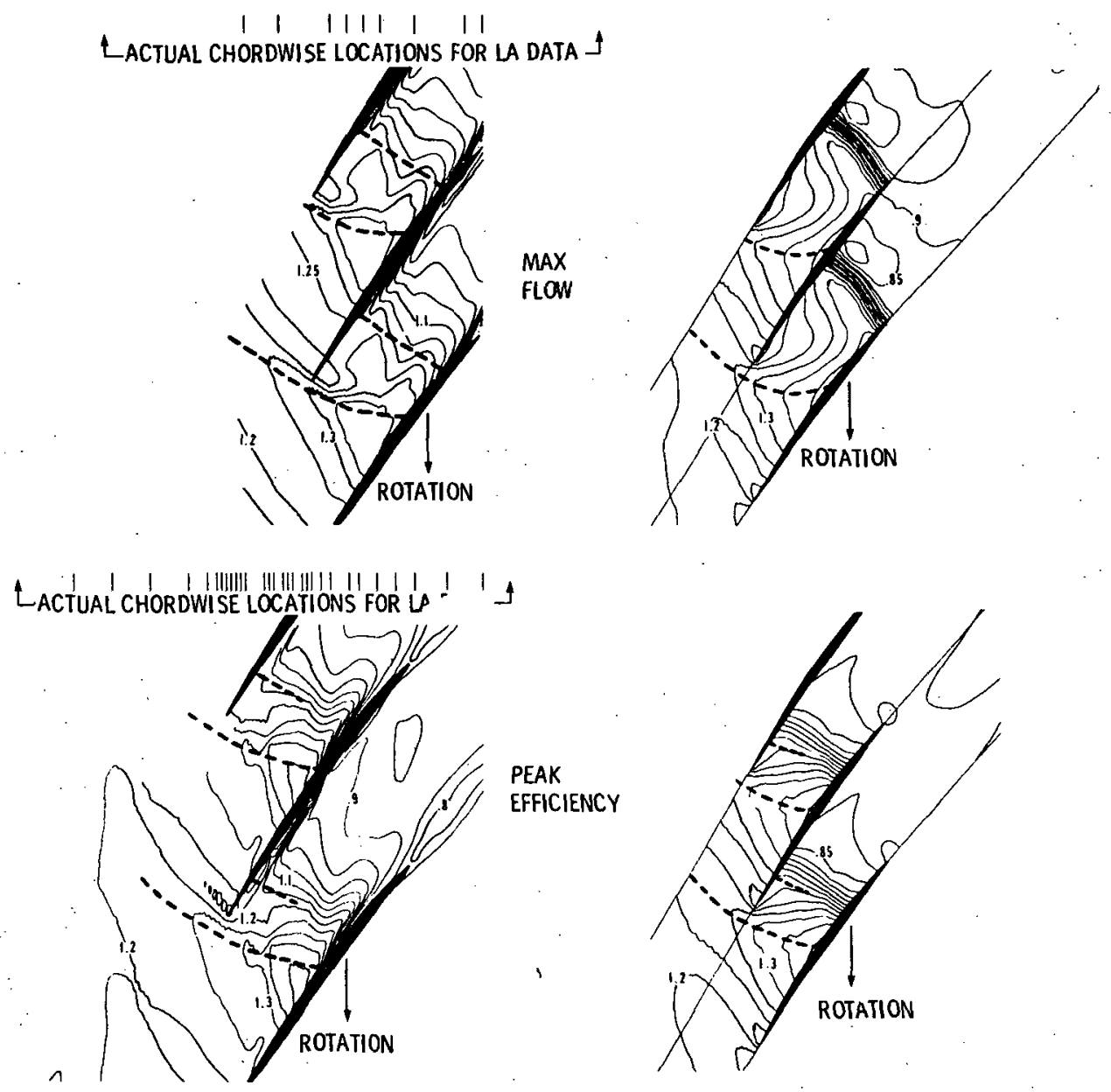

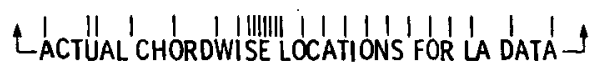

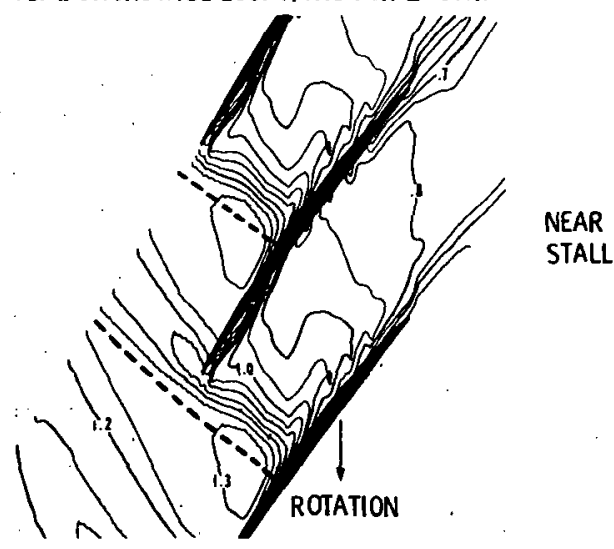

LA DATA

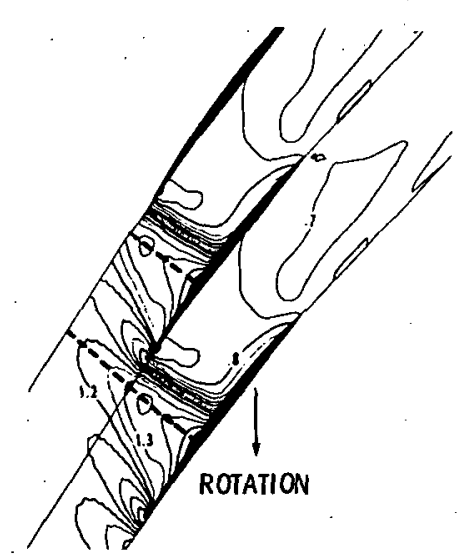

ANALYSIS

Figure 5. - Contour plots of relative.Mach number at $30 \%$ span from the tip for max flow, peak efficiency, and near stall flow points: comparison of LA survey results with analysis results. ----Shock location. 

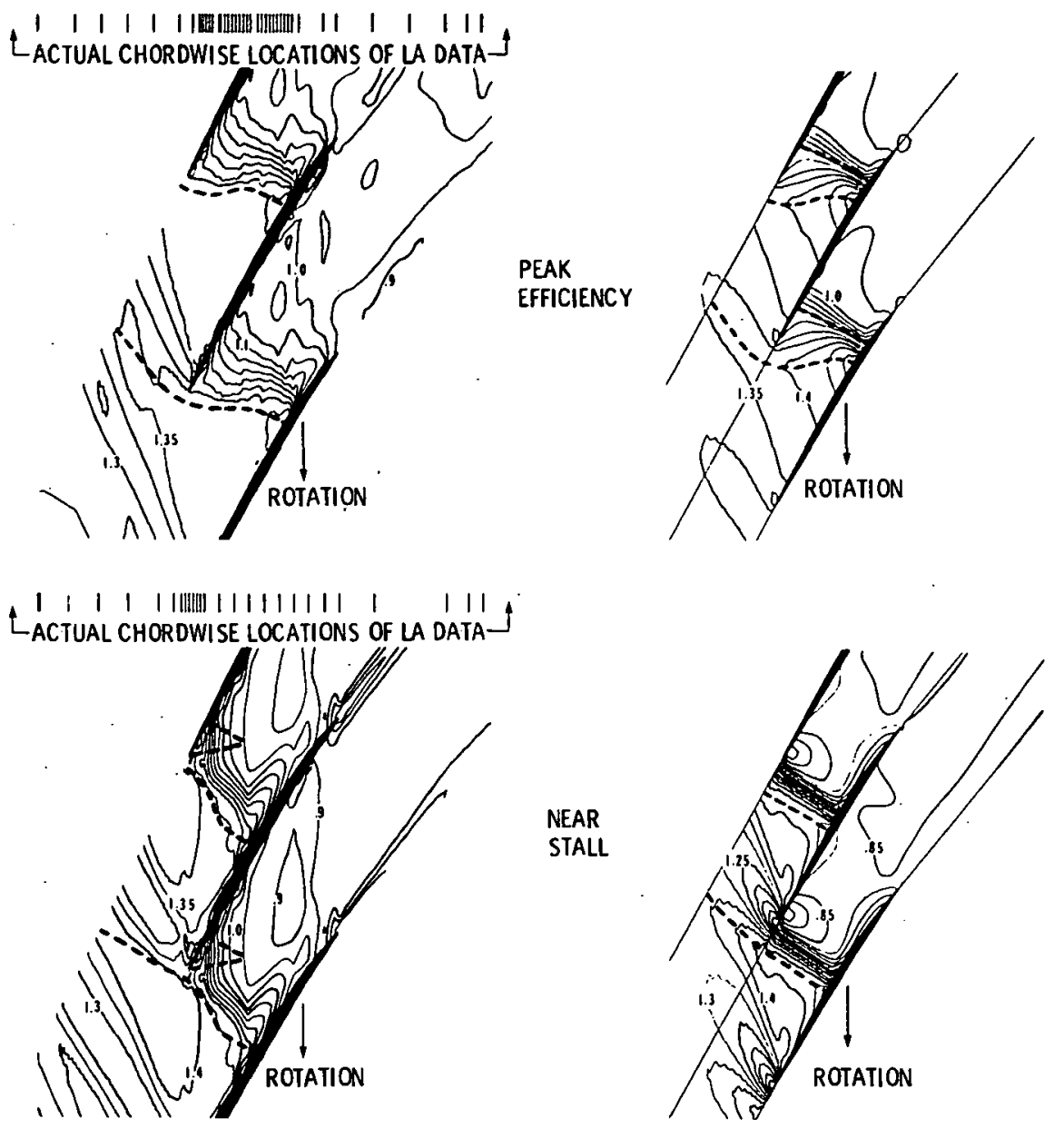

LA DATA

ANALYSIS

(a) $10 \%$ span.

Figure 6. - Contour plots of relative Mach number at $10 \%$ span from the tip for the peak efficiency and near stall flow rates: comparison of LA survey data with analysis results --- shock location. 
II | | IIIII 111111111111

tACTUAL CHORDWISE LOCATIONS FOR LA DATA ${ }^{\star}$

0

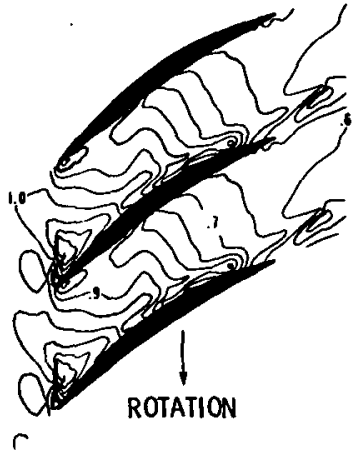

PEAK

EFFCIENCY

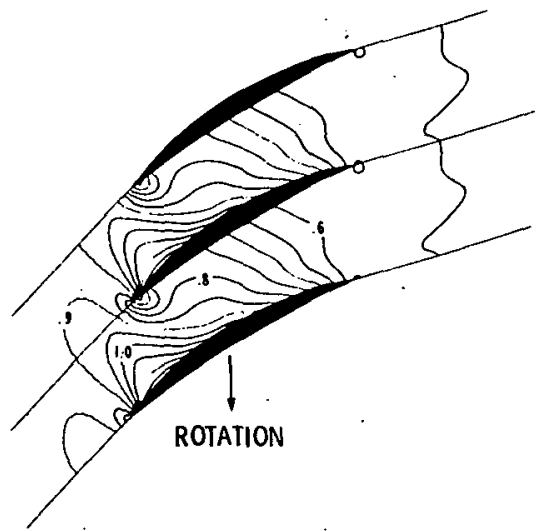

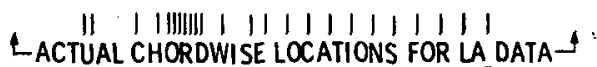

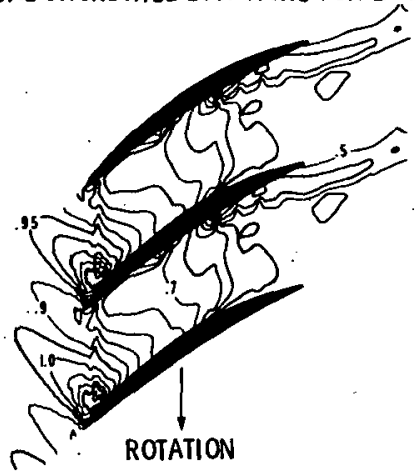

LA DATA

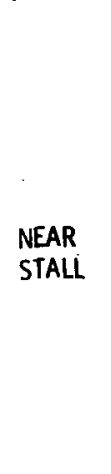

(b) $70 \%$ span.

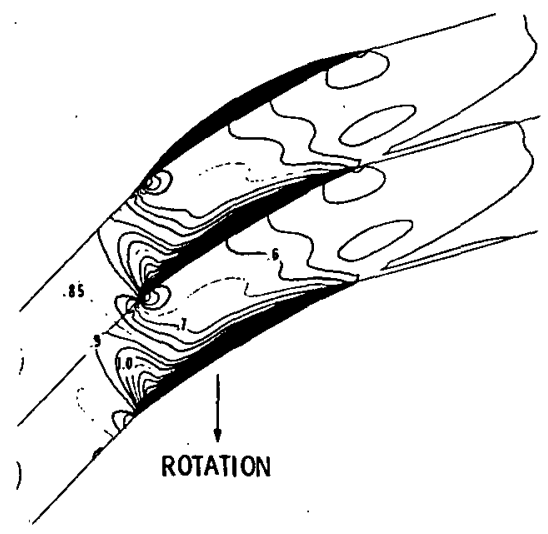

ANALYSIS

Figure 6. - Concluded. 

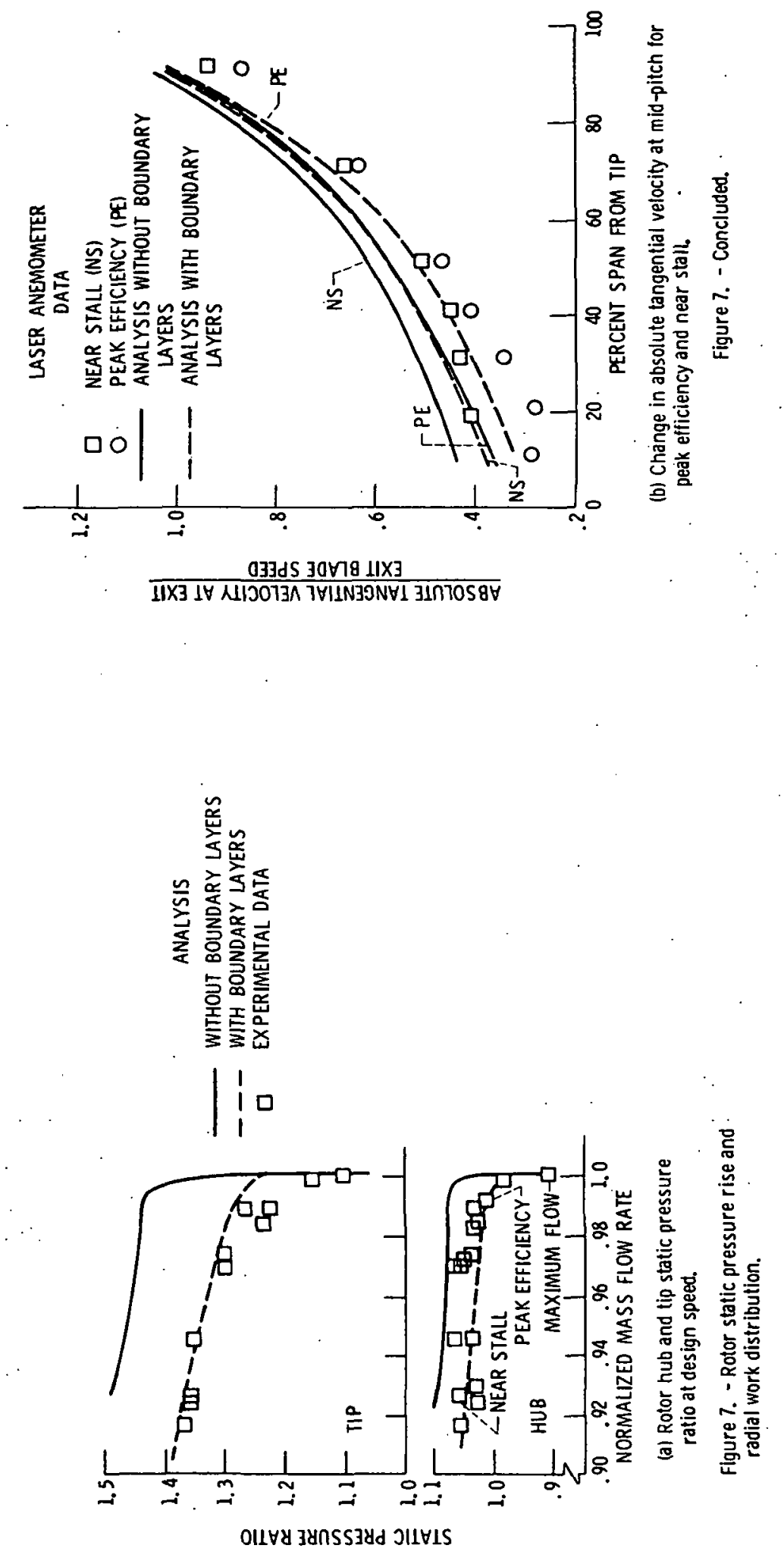


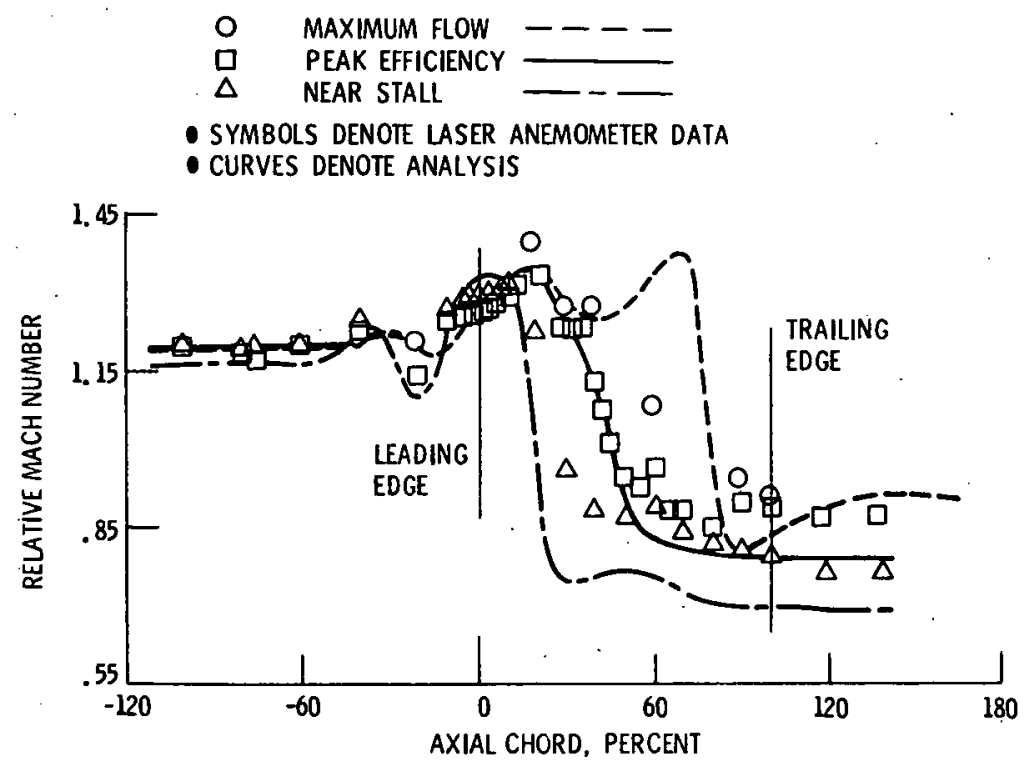

Figure 8. - Variation in relative Mach number with percent chord at mid-pitch for three flow points at 30-percent span from the tip. 


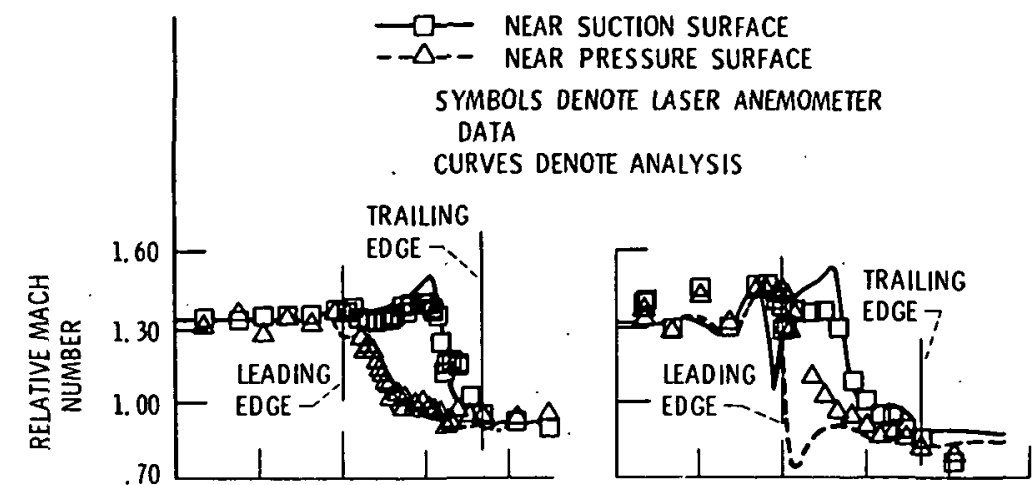

(b) 10-Percent span from tip, near

(a) 10-Percent span from tip peak efficiency.

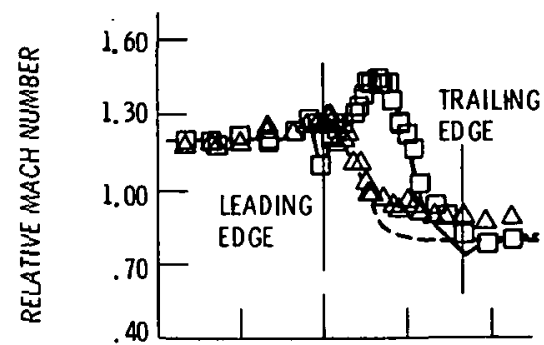

(c) 30-Percent span from tip. peak efficiency.

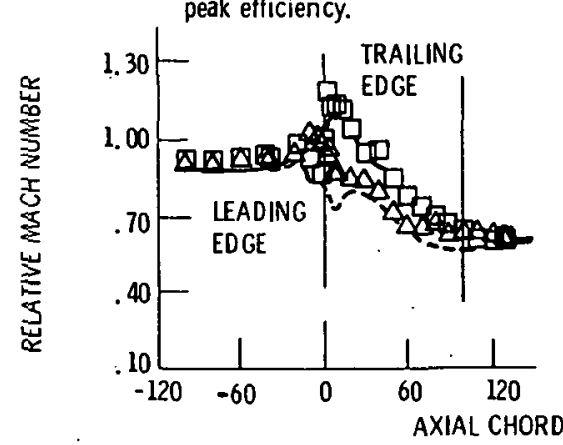

(e) 70-Percent span from tip. peak efficiency. stall.

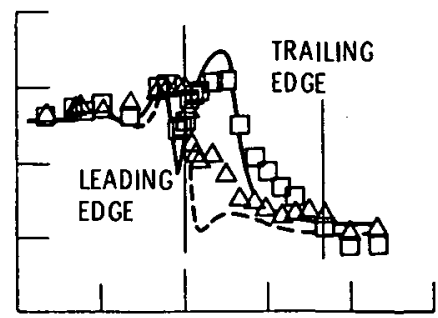

(d) 30-Percent span from tip, near stall.

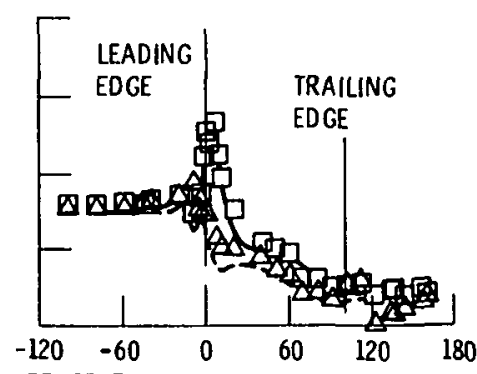

(f) 70-Percent span from tip. near stall.

Figure 9. - Variation in relative Mach number with percent chord at three spanwise locations for peak efficiency and near stall flows. 


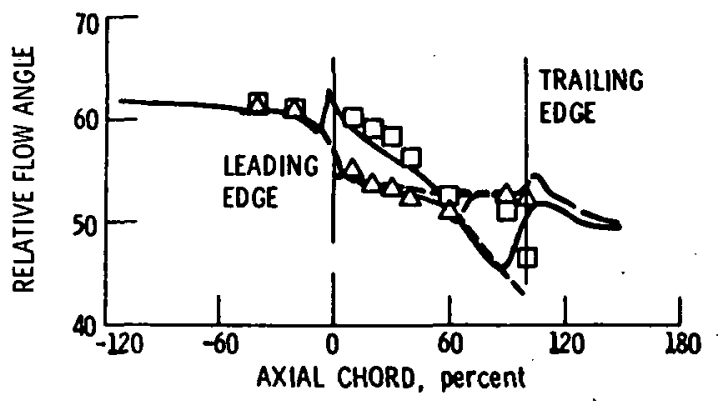

(a) Maximum flow point

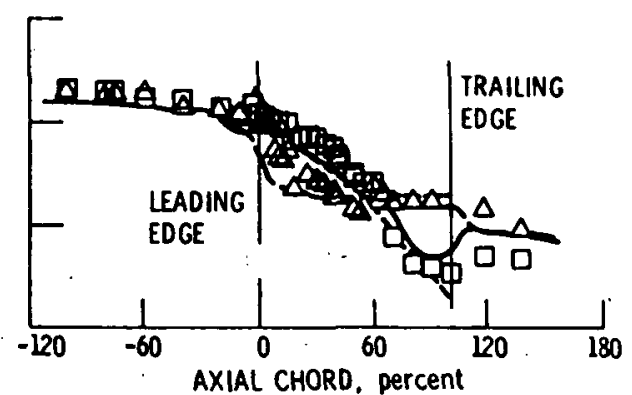

(b) Peak efficiency point

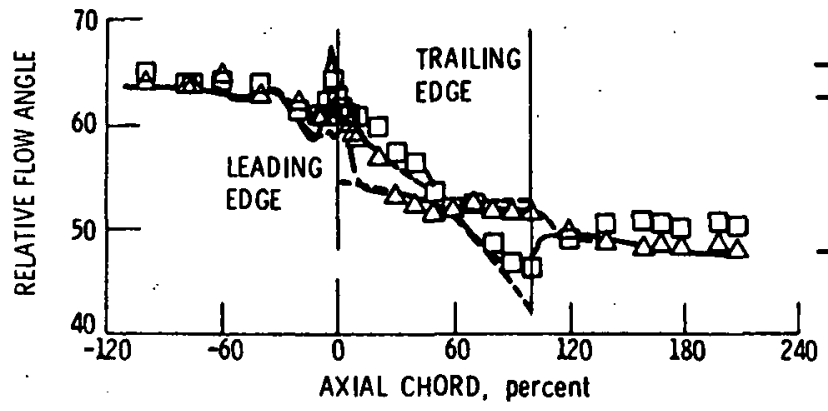

NEAR SUCTION SURFACE

- $\triangle$ - NEAR PRESSURE SURFACE

SYMBOLS DENOTE LASER ANEMOMETER

DATA

CURVES DENOTE ANALYSIS

- - BLADE SURFACE ANGLES

(c) Near stall point

Figure 10. - Variation in relative flow angle with percent chord along the speed line for experiment and analysis at 30-percent span from the tip.

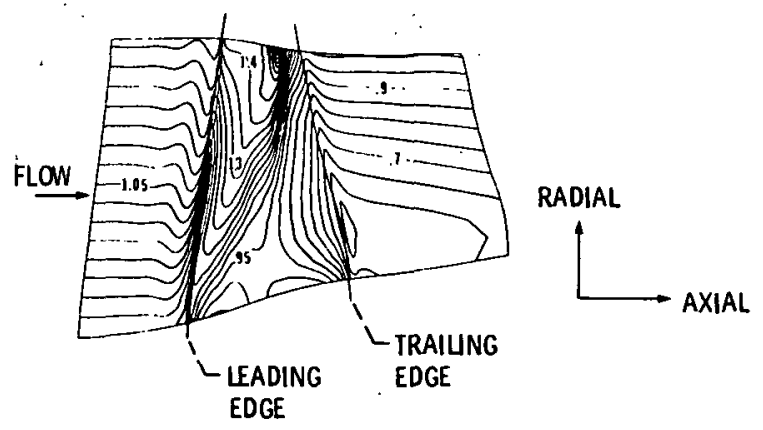

(a) Peak efficiency.

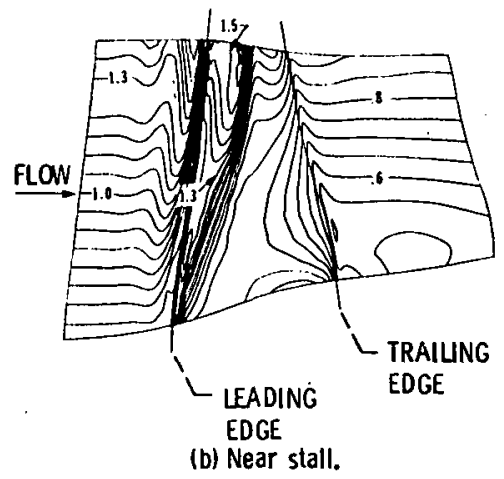

(b) Near stall.

Figure 11. - Contours of suction surface relative Mach nümber projected on the meridional hub-to-shroud plane. analysis results only. 


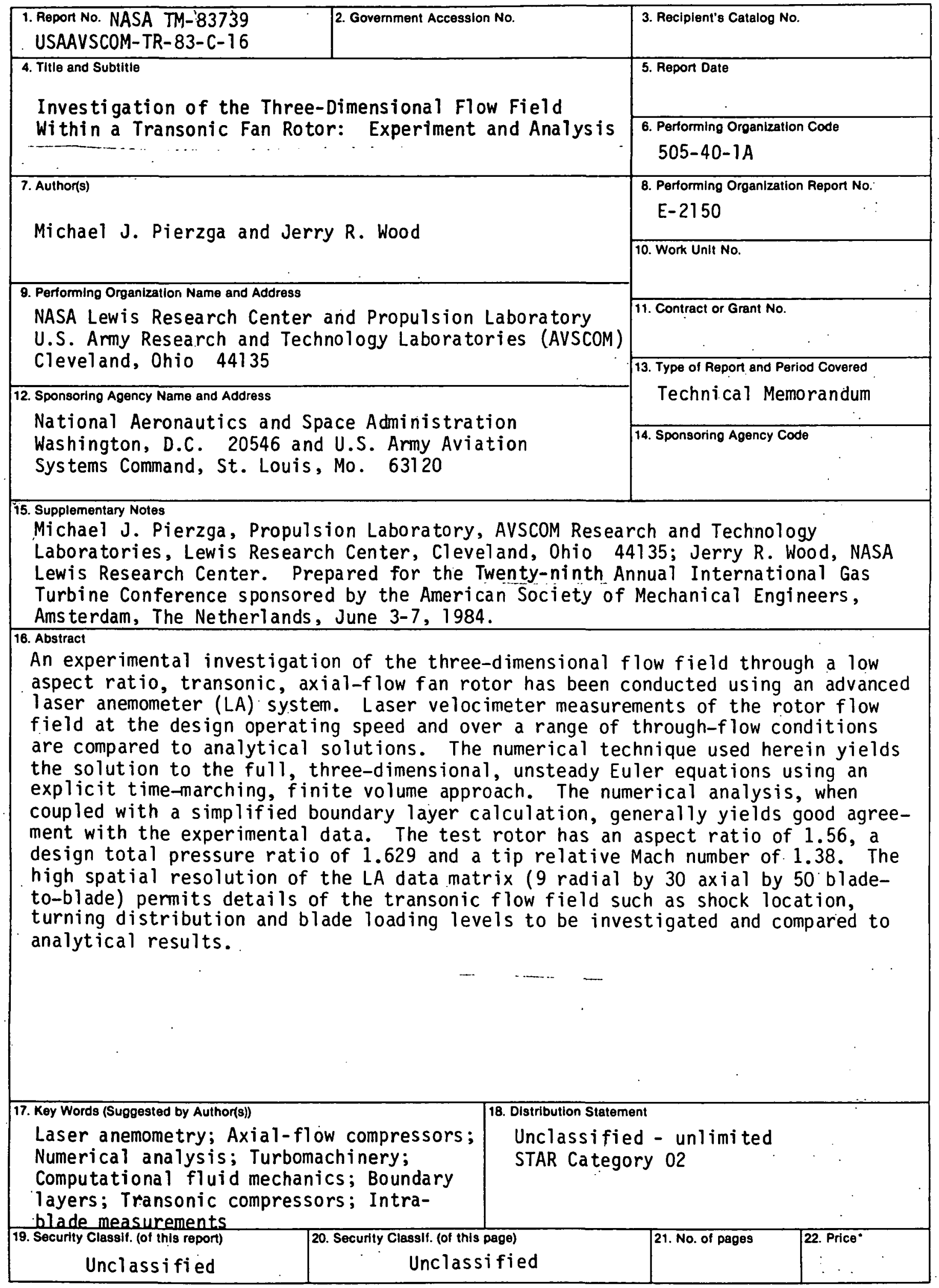

"For sale by the National Technical Intormation Service, Springfield, Virginia 22161 
National Aeronautics and

Space Administration

Wastington, D.C.

20546

Official Business

Penalty for Private Use, $\mathbf{5 3 0 0}$
SECCIAL FOUNTM ClASS MAIL book

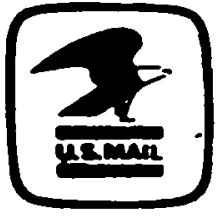

Portoges and Fees Paid

Mational Aeronsutics and Spece Administration NASA-451 